\title{
PETER BEHRENS E O DESIGN INDUSTRIAL
}

Francielly Felix de Freitas, Jaquelyne Soares Balsani, Luana Carla de Jesus Bernardino, Mahyani Rosa Cruz, Talita Eduarda Reis de Jesus, Tatiane Rodrigues Freitas, Korina Costa

Universidade do Oeste Paulista - UNOESTE. Curso de Arquitetura e Urbanismo, Presidente Prudente - SP.

\section{RESUMO}

O presente trabalho tem por objetivo fazer o estudo do arquiteto e designer alemão Peter Behrens, contextualizando os acontecimentos na Alemanha, paralelamente em outras localidades do mundo após a eclosão da Revolução Industrial e consequentemente seus efeitos na relação entre a arte e indústria, tendo suas produções concentradas nos anos finais do século XIX e iniciais do século XX. Enfatizando a configuração da Fábrica de Turbinas para melhor compreensão de suas características. Por fim, demonstrar a representatividade e a contribuição de Peter Behrens na arquitetura e design industrial para aquela época assim como para as gerações posteriores, tendo sido um dos precursores do movimento modernista, que irá realmente ocorrer no século XX, mais especificamente no intervalo entre a Primeira e a Segunda Guerra Mundial.

Palavras-chave: Peter Behrens, Deutsche Werkbund, Fábrica de Turbinas, design e indústria.

\section{PETER BEHRENS AND INDUSTRIAL DESIGN}

\begin{abstract}
The present work aims to study the German architect and designer Peter Behrens, contextualizing the events in Germany, parallel elsewhere in the world after the outbreak of the Industrial Revolution and consequently its effects on the relationship between art and industry, and their productions concentrated in the final years of the nineteenth and early twentieth century. Emphasizing configuration Plant Turbines for better understanding of their features. Finally, to demonstrate the representation and the contribution of Peter Behrens in architecture and industrial design for that time as well as later generations, having been one of the pioneers of the modernist movement, which will actually occur in the twentieth century, more specifically in the range between first and the Second World War.
\end{abstract}

Keywords: Peter Behrens, Deutsche Werkbund, Factory turbines, design and industry. 


\section{INTRODUÇÃO}

No início do século XIX, a civilização vivia um momento de efervescência e de múltiplas transformações. Desde o início da Revolução Industrial por volta de 1780 na Inglaterra, a sociedade européia verificou os efeitos que esta nova forma de trabalhar manifestava em todas as áreas da civilização.

Contudo, na Alemanha ainda era forte a presença da produção manual e sua população era maioria de tradição agrícola. Somente em 1862 chega ao sul do país uma inicialização industrial, enquanto que outros países como França e Inglaterra estavam relativamente à frente nesta questão. Foi a partir então de 1870 que as máquinas e fábricas passaram cada vez mais a fazer parte do contexto alemão.

A industrialização alemã, embora tardia, estava agora no processo de mecanização e ampliação de mercados, aspirando assim, por uma rápida industrialização e, consequentemente, uma posição concorrente no mercado industrial.

Contudo, a produção industrial alemã era considerada pelos críticos inferior a dos demais países industrializados. Afirmavam que a preocupação da Alemanha era somente em concorrer com as nações líderes industriais, entretanto, isto passa a ser repensado e os cuidados com o design e a qualidade dos produtos se tornam fatores essenciais para a prosperidade do país.

Porém, a Alemanha não estava engajada na qualidade de seus produtos, na função aliada à estética, mas sim, em conseguir posição para ganhar da concorrência, no caso os ingleses, neste sentido, Franz Reuleaux (2008, pag. 130), complementa dizendo:

Os produtos alemães eram baratos e grosseiros e a indústria alemã deveria desistir dos princípios baseados exclusivamente na concorrência dos preços e, em vez disso, usar a capacidade intelectual e a habilidade do operário em apurar o produto e fazê-lo tanto mais intensivamente quanto mais esse produto estiver próximo da arte.

Frente a essa discussão e com a intenção de melhorar a produção industrial, que um grupo de arquitetos, artistas, artesãos, industriais (pessoas ligadas no meio industrial), fundaram em cinco de outubro de 1907 em Munique, a Deutsche Werkbund (DWB) ou Federação Alemã de Ofícios.

O pensamento da Werkbund era a cooperação entre arte, indústria e artesanato para a melhoria da atividade comercial, apoiando assim a produção em massa dos objetos, porém buscando criar uma identidade que os caracterizassem, não somente a simples confecção objetual. 
Contudo essa federação aspirava por idéias progressistas na qual tinham por objetivo elevar a qualidade estética dos produtos fabricados na Alemanha, isto conciliando o esforço artístico com a produção industrial em massa.

Portanto, a Deutsche Werkbund pode ser entendida como o nascimento do Design propriamente dito. Os participantes do movimento não entendiam o objeto industrial de forma simplesmente utilitária, mas como forma de manifestar a arte nessa nova sociedade industrial.

Arquitetos como Richard Riemerschmid que foi parte do movimento modernista na Alemanha, defendia a idéia de que o design devia interagir com a produção industrial, pois acreditava-se que a única forma de fazer os produtos acessíveis à sociedade trabalhadora era a produção em massa.

Propunha que os artistas trabalhassem em conjunto com as indústrias no desenvolvimento de seus produtos, isto na tentativa de melhorar a condição de trabalho de seus operários e que estes pudessem intervir no processo de produção.

Em partes se deve as inspirações do movimento Arts and Crafts ocorrido na Inglaterra, contudo não pretendia um retorno nostálgico ao artesanato medieval, como era característico desse movimento, mas sim, reviver o estatuto do artesanato e sua aplicação à produção industrial.

Segundo Benevolo (2009, p. 374), “o objetivo da Werkbund - reza o estatuto - é enobrecer o trabalho artesanal, coligando-o com a arte e a indústria". Diferentemente do movimento inglês, os alemães não se voltaram contra a indústria, mas procuraram resolver o problema juntamente com ela, aceitando a divisão de trabalho do processo produtivo industrial. Buscavam uma produção aliada à arte que dialogasse com aquele novo momento caracterizado pela rapidez, padronagem, produção em série, contudo sem perder o caráter e a identidade do produto.

Para o movimento Deutsche Werkbund, a indústria era parte dos novos tempos e, através dela, poderia ter um mundo melhor, onde o artista e o artesão unificados, teriam melhores condições de vida e qualidade nos produtos industriais.

Posteriormente, essa ideia passa a influenciar outros movimentos como a criação da escola Bauhaus em 1919 e das normas DIN em 1917.

\section{METODOLOGIA}

A pesquisa foi desenvolvida com base nos livros que tratam de assuntos da época em estudo e suas características arquitetônicas. Além de pesquisas na internet, foi somado o conhecimento adquirido no ambiente acadêmico.

Cuja investigação se fundamentará na abordagem qualitativa de pesquisa, utilizando-se da 
pesquisa de levantamento bibliográfico e da pesquisa documental, que segundo Teixeira (2000, p. 137), busca a correlação entre a teoria e os dados, entre o contexto e a ação, a partir da compreensão dos fenômenos por meio de sua descrição e interpretação. Para o trabalho com o estudo do tipo de levantamento bibliográfico ocorrerá inicialmente um levantamento das principais produções no contexto nacional de estudos, considerando a peculiaridade do objeto de estudo.

Desse modo, percebe-se que a pesquisa qualitativa vale-se do método indutivo, segundo o qual parte da observação, da análise dos fatos particulares, dos registros para compor um quadro compreensivo para então constituir a generalização universal, ou seja, a teoria. O processo de indução vale-se do princípio do empirismo, no qual o conhecer é dar significado à realidade (KÖCHE, 1997, p. 62)

\section{PETER BEHRENS}

Arquiteto e designer alemão Peter Behrens nasceu em Hamburgo em 1868 e morreu em Berlim em 1940. Filho de uma família rica de Hamburgo, seria órfão aos 14 anos de idade. Estudou pintura em Kalsruhe e em Dusseldorf, deslocando-se em 1890 para Munique onde atuou como pintor e artista gráfico se aliando ao movimento Art Nouveau. Depois de frequentar a Escola de Belas Artes de Hamburgo, partiu novamente para Munique em 1897, durante o período de renascimento das Arts and Crafts na Alemanha.

No início do século, produziu obras marcantes na pintura, arquitetura, design gráfico e industrial, abrindo um território amplo para as gerações subsequentes. Hoje é considerado como o primeiro e um dos mais importantes designers da História. Foi um dos arquitetos mais influentes da Alemanha e um dos fundadores da Deutsche Werkbund. Também consultor artístico da AEG empresa elétrica da época.

Behrens foi um dos mais importantes designers alemães do século XX. Suas soluções de design simples, práticas e racionais foram intensamente influentes para a formação do Modernismo. Além de inspirar vários artistas posteriores, incluindo Le Corbusier, Mies Van der Rohe e Walter Groupius, fundador da Escola Bauhaus.

Em 1907 o diretor da AEG (Companhia Elétrica Geral) nomeia-o como consultor artístico, sendo esta a primeira vez que uma empresa contrata um arquiteto para aconselhar sobre todos os aspectos do design. Nesta função, Behrens atuou como projetista dos edifícios administrativos, dos complexos residenciais para funcionários da empresa e do parque industrial, incluindo também a 
criação de produtos elétricos, como chaleiras, ventoinhas e relógios de forma a racionalizar os métodos de produção.

Esta situação permite-lhe desenvolver a aspirada relação entre arquitetura, desenho e indústria, o que o transforma num dos profissionais mais relevantes na Alemanha nessa época.
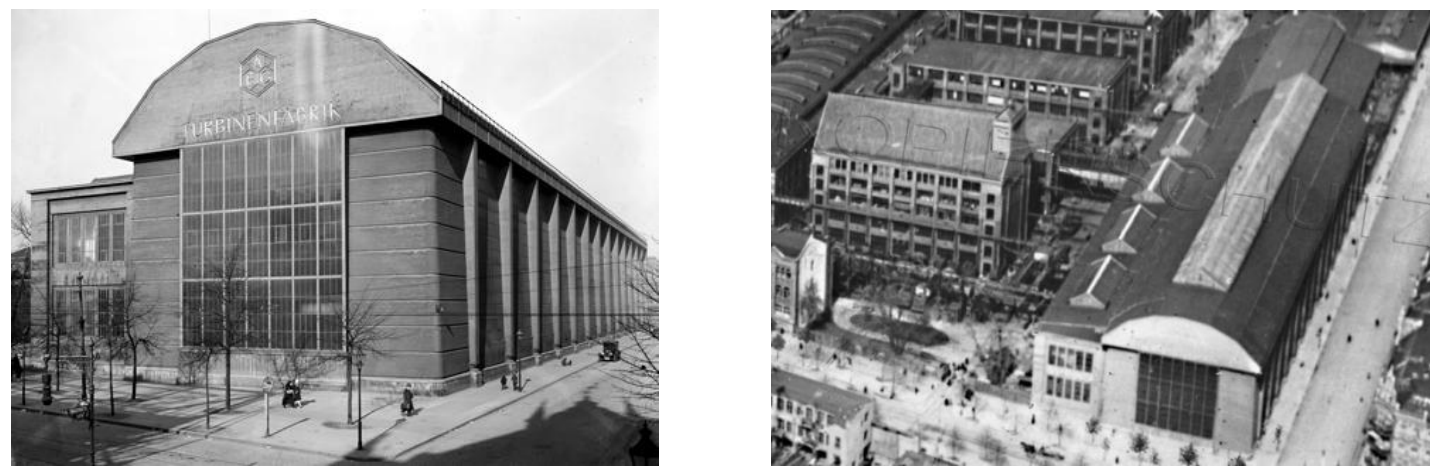

Figura 1. Behrens, Fábrica de Turbinas AEG, Berlim 1908-1909 (Imagem de 1927) e sua Vista aérea Fonte: http://elojoenelcielo.wordpress.com/2013/11/19/un-regalo-de-cumpleanos/

Dentre as principais realizações de Peter Behrens está a Turbinen Fabrik ou Fábrica de Turbinas localizada em Berlim, na qual é considerada a precursora da arquitetura moderna industrial na Alemanha. A Fábrica de Turbina AEG colocou a indústria alemã no auge internacional. É um dos edifícios mais significativos do proto racionalismo, sendo um dos primeiros edifícios alemães a ser construído com materiais industrializados, como o vidro o concreto, que eram pouco utilizados na época.

Frampton descreve a Fábrica de Turbinas como "Obra de arte consciente, um templo ao poder da indústria" (2008, p. 132). Isso induzido principalmente em sua forma, esta que é constituída por um extenso complexo, sendo o traçado deste geométrico, com frontão tripartido (poligonal) e uma elevada altura na qual atribui a esse edifício essa monumentalidade da era industrial. Esses conceitos arquitetônicos atribuem à simplicidade formal um requisito fundamental onde percebe-se que o ritmo e a padronização de partes da mesma formam um conjunto homogêneo.

Sendo que os motores das turbinas eram significamente grandes, requeria portanto espaço adequado para isso. Assim, Behrens desenhou um edifício retangular, muito alongado, que atinge 207 metros de comprimento, de modo que os operários pudessem desenvolver o trabalho em uma linha de trabalho.

No interior desta, Behrens considerou os conceitos de produtividade, organização do centro de produção e o transporte dos produtos e das matérias- primas. 

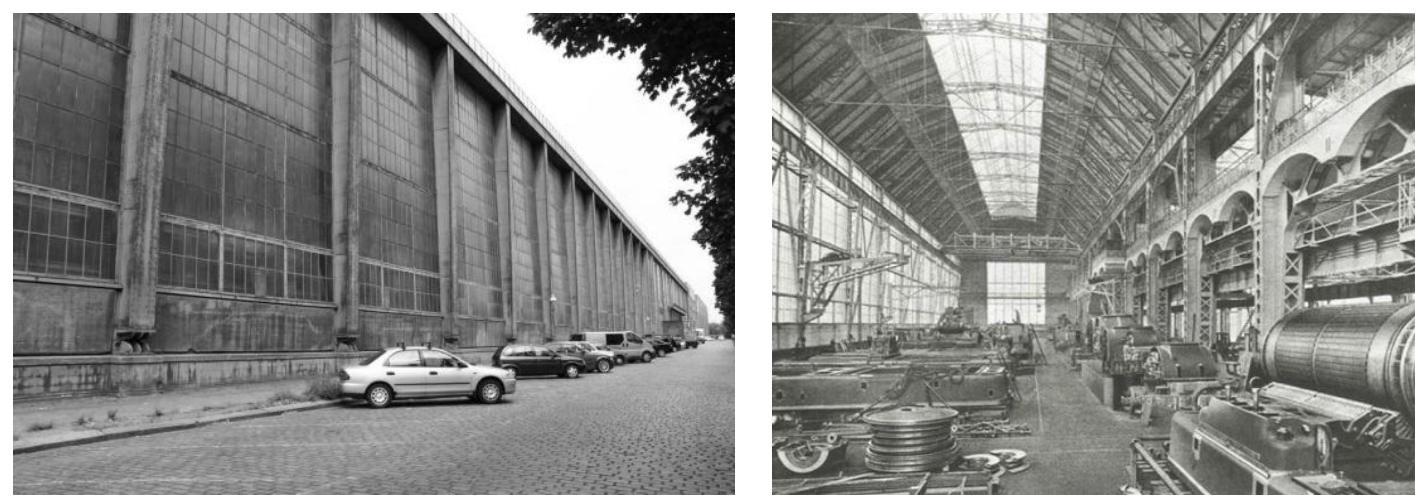

Figura 2. Behrens, Fábrica das Turbinas AEG, Berlim - Vista lateral e Vista interna Fonte: http://elojoenelcielo.wordpress.com/2013/11/19/un-regalo-de-cumpleanos/

A fábrica se caracteriza por seu caráter utilitário, aplicando regras de desenho industrial no desenho arquitetônico. Por ser um edifício que prioriza a funcionalidade, seus elementos são direcionados para que propiciem isso, resultando assim, em um diálogo construtivo tanto interno quanto externo.

Além de a Fábrica de Turbinas retratar a atual configuração da era industrial, esta era composta por uma estrutura metálica promovendo grande amplitude de espaços (o que era necessário até mesmo pelo seu caráter), ressaltando novamente a ideia de funcionalidade do edifício. Behrens não só pensava nas necessidades industriais da empresa, porém procurou conciliar a função com o conforto daqueles que trabalham nessas instalações.

Também é notável uma explícita preocupação com a ergonomia, pois se levava em consideração variados fatores do ponto de vista do conforto do trabalhador, como o nível de luminosidade, uso de vidros nas paredes laterais, o que além de transparecer luz por toda a fábrica contribuía para a ventilação interna.
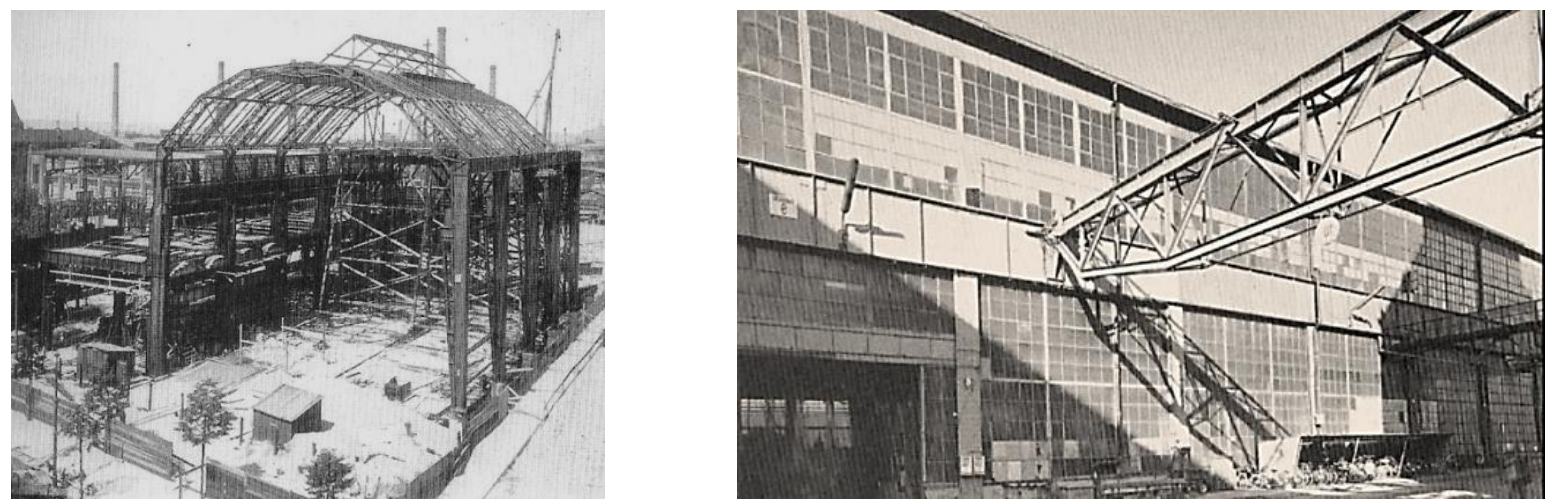

Figura 3. Behrens, Fábrica das Turbinas AEG, Berlim - Edifício em construção e Estrutura exposta Fonte: file:///C:/Users/HP/Downloads/industria\%20e\%20arquitectura.pdf

Dentre os materiais utilizados na construção, o emprego do aço, concreto e vidro é extremamente significativo, reforçando assim a introdução do uso da tecnologia e consequente 
inovação construtiva. Efetivamente neste edifício, as estruturas de aço são visíveis e o vidro é usado na fachada, laterais e partes da cobertura da fábrica.

Behrens utilizou as estruturas metálicas segundo as técnicas da época e explorou as potencialidades do betão nas fachadas e paredes, também é caracterizada pela ausência de decoração, conferindo-Ihes a obra robustez. Portanto, os materiais empregados como a estrutura metálica exposta e o vidro, oferecem uma resposta lógica e funcional das necessidades construtivas.

\section{CONCLUSÃO}

Peter Behrens teve um papel primordial na constituição da Arquitetura, Design Industrial e na criação da identidade corporativa, isso explícito no desenvolvimento de produtos para AEG, mas principalmente por fomentar a ideia de que estes poderiam fazer parte do meio industrial fazendo edifícios e produtos que beneficiassem a sociedade como um todo.

Deixando assim, importantes contribuições tanto na Arquitetura como no Design, na qual teve uma fundamentação firmada na conciliação entre a arte, indústria e produção industrial.

Suas ideias refletiram para diferentes e amplas visões, abrindo assim novos caminhos para a Arquitetura Moderna, marcada pela versatilidade e harmônica atuação desse arquiteto que revolucionou não somente seu tempo, mais deixou um legado enriquecedor, influenciando assim as posteriores gerações.

\section{REFERÊNCIAS}

BENEVOLO, Leonardo; História da arquitetura moderna, Editora Perspectiva, São Paulo, 2009.

DENIS, Rafael Cardoso. Uma introdução à história do design. São Paulo: Editora Edgard Blücher, 2000.

FRAMPTON, Kenneth; História crítica da arquitetura moderna, Martins Fontes Editora, São Paulo, 2008.

GLANCEY, Jonathan - História da Arquitetura. Edições Loyola, Rio de Janeiro, 2007. http://www.aeg.com.pt/Plan--Design/AEG-Heritage/http://www.behrenspeter.com/http://www.arqueologiaypatrimonioindustrial.com/2010 0501 archive.html

GROPIUS, Walter Gropius; Bauhaus: Arquitetura, Editora Perspectiva, São Paulo, 1974. PEVESNER, Nikolaus, 1960, 1974. Os Pioneiros do Desenho Moderno - de William Morris e Walter Gropius.

TIETZ, Jurgen; História da arquitetura contemporânea, Ed. H.F. Ullmann, Tandem Verlag GmbH, 2008. 